Number of pages: 28

Number of tables: 7

Number of figures: 3

Number of references: 12

\title{
The vibration discomfort of standing people: relative importance of fore-and-aft, lateral, and vertical vibration
}

\author{
Olivier Thuong and Michael J Griffin \\ Human Factors Research Unit \\ Institute of Sound and Vibration Research \\ University of Southampton, SO17 1BJ \\ United Kingdom
}

Correspondence address:

Professor Michael J Griffin

Human Factors Research Unit

Institute of Sound and Vibration Research

University of Southampton

Southampton SO17 1BJ

England

Telephone: (+44) 02380592277

Facsimile: (+44) 02380592927

E-mail: M.J.Griffin@soton.ac.uk 


\begin{abstract}
Few studies have compared the discomfort caused by vibration in different directions, and few have investigated the vibration discomfort of standing people. This study was designed to compare the discomfort experienced by standing people exposed to sinusoidal vibration in the fore-and-aft, lateral, and vertical directions. Using the method of magnitude estimation, 12 subjects estimated the discomfort caused by $4-\mathrm{Hz}$ sinusoidal vibration at 10 different magnitudes. At $4 \mathrm{~Hz}$, subjects were less sensitive to lateral vibration than to fore-and-aft vibration $\left(K_{y} / K_{x}=0.71\right)$, and more sensitive to vertical vibration than to horizontal vibration $\left(K_{z} / K_{x}=1.95 ; K_{z} / K_{y}=2.77\right)$. Previous findings showing how the discomfort of standing people depends on the frequency of fore-and-aft, lateral, and vertical vibration were used to define frequency weightings that reflect relative sensitivity to vibration in each direction. The frequency weightings differ from those appropriate for seated people, and differ from the weightings for standing people in current standards that were mostly derived from understanding of the discomfort of seated people.
\end{abstract}

\title{
Highlights
}

Shows how direction of vibration affects the vibration discomfort of standing people.

Shows vibration discomfort is different in seated and standing people.

Standards for predicting vibration discomfort of seated and standing people can be improved. 


\section{Introduction}

To minimise the vibration discomfort of passengers standing in any form of transport it is necessary to understand how the discomfort caused by the vibration can be predicted.

In road, rail, sea, and air transport, vibration occurs with various magnitudes, frequencies, waveforms, durations, and directions. Studies of the discomfort of seated and standing people have compared the effects of different magnitudes, frequencies, waveforms, and durations of vibration presented within a direction (e.g., fore-and-aft, lateral, or vertical). There has been little consideration of the relative discomfort caused by vibration in different directions, probably because of the limited availability of simulators suitable for shaking people in several directions. To minimise discomfort, it would be helpful to know which direction of vibration causes greater discomfort.

British Standard 6841 (1987) and International Standard 2631-1 (1997) assume that fore-and-aft and lateral vibration cause similar discomfort when they have similar magnitudes. Vertical vibration is assumed to cause greater discomfort than fore-andaft or lateral vibration at frequencies greater than $3.15 \mathrm{~Hz}$, but less discomfort at lower frequencies. The standards offer the same methods for predicting the vibration discomfort of seated and standing people.

The findings of experimental studies are not entirely consistent with the standards. Over the range 3 to $10 \mathrm{~Hz}$ various studies with seated subjects have concluded that sensitivity to fore-and-aft vibration can be greater than sensitivity to lateral vibration (Griffin et al., 1982; Mistrot et al., 1990). Although the standards give the same methods for seated and standing people, some studies suggest differences in the subjective responses of seated and standing people (e.g. Oborne and Boarer, 1982). The relative sensitivity to vibration in different directions has not previously been investigated experimentally for standing people.

The experiment reported here was conducted to determine the relative sensitivity of standing people to fore-and-aft, lateral, and vertical vibration. An earlier study determined how the discomfort of standing people depends on the frequency of vibration in each of the three directions of excitation (over the range 0.5 to $16 \mathrm{~Hz}$ ), so it was only necessary to investigate relative discomfort at one frequency $(4 \mathrm{~Hz})$ to obtain the information needed to calculate relative sensitivity at other frequencies. 
The findings are used to adjust the frequency weightings obtained in the previous study with standing people exposed to vibration in a single direction and provide weightings that can be used to evaluate and compare vibration in different directions.

\section{Method}

\subsection{Motions}

Standing subjects experienced $4-\mathrm{Hz}$ sinusoidal vibration of 6 -seconds duration in the fore-and-aft, the lateral, or the vertical direction. Motions were presented in pairs, with a reference motion in one direction followed by a test motion in a different direction. All six possible pairings of the direction of the reference and test motions were studied in six groups (Table 1).

\section{TABLE 1 AROUND HERE}

Within each group, the reference motion was presented at a constant magnitude, and the test motions were presented at 10 magnitudes, in steps of $1.5 \mathrm{~dB}$ (Table 2). From preliminary studies, the magnitudes of the reference motions were selected to cause approximately equivalent discomfort in the three directions. Compared to fore-and-aft vibration, the reference was $2 \mathrm{~dB}$ lower in the lateral direction and $2 \mathrm{~dB}$ higher in the vertical direction (Table 2). The ranges of the test stimuli were lowered and raised by corresponding amounts.

\section{TABLE 2 AROUND HERE}

\subsection{Equipment}

The motions were produced using a six degree-of-freedom motion simulator (Figure 1) in the Human Factors Research Unit at the Institute of Sound and Vibration Research. The simulator can generate fore-and-aft, lateral, vertical, pitch, roll, and yaw oscillation, with maximum displacements of $\pm 250 \mathrm{~mm}$ in the fore-and-aft and lateral directions and $\pm 500 \mathrm{~mm}$ in the vertical direction. The simulator was controlled by a Pulsar Digital Controller (Servotest Systems, Egham, UK). The motion stimuli were generated in Matlab (version R2009a) using the Matlab Toolbox HVLab HRV (version 1.1) developed by the Human Factors Research Unit (University of Southampton).

FIGURE 1 AROUND HERE 
The vibration of the platform was monitored using Setra $141 \mathrm{~A}$ capacitive accelerometers secured to the centre of the simulator table. The signal from the transducer was sampled by Pulsar Digital Controller software at 256 samples per second after low pass filtering at $64 \mathrm{~Hz}$.

\subsection{Subjects}

Twelve healthy male university students and staff with median age 26 years (range 23 to $30 \mathrm{y}$ ), stature $175 \mathrm{~cm}$ ( 165 to $198 \mathrm{~cm}$ ), weight $66 \mathrm{~kg}$ (50 to $104 \mathrm{~kg}$ ) participated in the study. They attended one session lasting approximately 90 minutes.

The experiment was approved by the Human Experimentation Safety and Ethics Committee of the Institute of Sound and Vibration Research at the University of Southampton.

\subsection{Conditions and posture}

The subjects wore socks, but no shoes, and a loose harness in case they should fall (Figure 1). The harness did not provide support or restrict movement when subjects stood as instructed. It was attached to an extruded aluminium frame secured to the table of the vibrator.

The subjects maintained an upright posture, with their knees locked, and their eyes closed. Their feet were parallel and separated so that their lateral 'base of support' (distance between the outer edges of their feet) was $350 \mathrm{~mm}$, the median shoulder width for adult males (Pheasant, 1988).

The subjects wore headphones delivering broadband noise at $65 \mathrm{~dB}(\mathrm{~A})$. The headphones also attenuated noise produced by the simulator when generating motions, which was always less then $51 \mathrm{~dB}(\mathrm{~A})$ at the location of the subjects.

\subsection{Procedure}

Subjects were exposed to one of the six reference motions in Table 1 followed by one of the corresponding 10 test motions in Table 2. The 60 pairs of motions were presented in a completely randomized order to minimize range effects. The procedure was then repeated so each of the 60 test stimuli was presented twice during the session. The objective was to reduce variability by using the geometric mean of the two estimations obtained for each test stimulus. 
The method of magnitude estimation, as used by Thuong and Griffin (2011a, 2011b) was employed to determine the discomfort caused the test motions. After the presentation of a pair of motions, subjects were asked to provide a number reflecting the discomfort caused by the test motion, assuming the discomfort caused by the reference motion was 100 . The subjects could ask for the pair of motions to be repeated if they were not sure of their judgement. Prior to commencing the experiment, subjects practiced magnitude estimation by judging the lengths of lines drawn on paper and by judging a few selected vibration stimuli. This provided an opportunity to check that they understood the procedure and also familiarised them with the type of vibration stimuli.

\subsection{Analysis}

\subsubsection{Determination of equivalent acceleration}

Stevens' power law (Stevens, 1975) was used to relate the magnitude estimates of subject discomfort, $\psi$, to the physical magnitudes of the test motions, $\varphi$ :

$$
\psi=k \varphi^{n}
$$

where $k$ (the 'constant' in Stevens' power law) and $n$ (the 'exponent', or rate of growth of sensation) are assumed to be constant at any frequency.

For each of the six groups of stimuli (Table 1) and for each subject, values of the exponent, $n$, and the constant, $k$, were determined by linear regression between the logarithms of the magnitude estimates and the logarithms of the acceleration of the test vibration (10 values) using bisquare weights to reduce bias from outlier values (Fox, 2002):

$$
\log \psi=\log k+n \log \varphi
$$

After the values of $k$ and $n$ had been determined, Equation (1) was rewritten:

$$
\varphi=\left[\frac{\psi}{k}\right]^{\frac{1}{n}}
$$

So, for each subject and each group (Table 1), the magnitude of the test motion equivalent in discomfort to the reference motion (i.e., corresponding to a magnitude estimate of 100) could be determined: 


$$
a_{e q(r e f-a x i s, t e s t-a x i s)}=\left[\frac{100}{k}\right]^{\frac{1}{n}}
$$

\subsubsection{Equivalence coefficients}

The discomfort caused by vibration in the test axis relative to the discomfort caused by vibration in the reference axis was estimated from the ratio of the magnitude of the reference motion to the equivalent magnitude defined in Equation (4), which will be referred to as the 'equivalence coefficient', $K$ (test-axis/ref-axis):

$$
K(\text { test }- \text { axis } / \text { ref }- \text { axis })=\frac{a_{\text {ref }(r e f-a x i s)}}{a_{e q(\text { test-axis } / \text { ref-axis })}}
$$

This coefficient is an estimate of the relative sensitivity to vibration in the test axis compared to the reference axis. For example, since the magnitude of the reference vibration in the $x$-axis was $0.5 \mathrm{~ms}^{-2}$ r.m.s., a value of $K$ (test-axis/ref-axis) $=2 K(x, y)=$ 2 would indicate that $0.25 \mathrm{~ms}^{-2}$ in the $y$-axis caused the same discomfort as $0.5 \mathrm{~ms}^{-2}$ in the $x$-axis, suggesting the subject was twice as sensitive to lateral vibration as to fore-and-aft vibration. Conversely, a value of $K(x, y)$ less than 1.0 would indicate that the subject was less sensitive to $y$-axis vibration than to $x$-axis vibration.

\subsubsection{Construction of inter-axis coefficients}

The equivalence coefficients calculated with Equation (5) could be biased by an order effect. For example, subjects may systematically overestimate the magnitude of the second motion when exposed to a test-reference pair of stimuli. Such bias can be minimized by averaging the results obtained in 'inverse' groups (i.e. $x / y$ and $y / x$; $x / z$ and $z / x ; y / z$ and $z / y$ ). For each pair of axes, 'unbiased estimates' of their relative sensitivities, $K_{2}$, were obtained:

$$
\begin{aligned}
& K_{2}(y / x)=\frac{1}{K_{2}(x / y)}=\sqrt{\frac{K(y / x)}{K(x / y)}} \\
& K_{2}(z / x)=\frac{1}{K_{2}(x / z)}=\sqrt{\frac{K(z / x)}{K(x / z)}} \\
& K_{2}(z / y)=\frac{1}{K_{2}(y / z)}=\sqrt{\frac{K(z / y)}{K(y / z)}}
\end{aligned}
$$


The unbiased coefficients, $K_{2}$, could be internally inconsistent. Robust inter-axis coefficients $\left(K_{3}\right)$ were constructed so that, unlike $K_{2}$, they were consistent, in the sense that:

$$
K_{3}(z / x)=K_{3}(z / y) K_{3}(y / x)
$$

The need for this condition to be true, and the desire to obtain formulae that are symmetrical over all three directions (i.e. the subjective assessments from all three directions are treated equally), lead to the three consolidated coefficients:

$$
\begin{aligned}
& K_{3}(y / x)=\left\{K_{2}(y / x)^{2}\left[K_{2}(z / x) K_{2}(y / z)\right]\right\}^{1 / 3} \\
& K_{3}(z / x)=\left\{K_{2}(z / x)^{2}\left[K_{2}(y / x) K_{2}(z / y)\right]\right\}^{1 / 3} \\
& K_{3}(z / y)=\left\{K_{2}(z / y)^{2}\left[K_{2}(x / y) K_{2}(z / x)\right]\right\}^{1 / 3}
\end{aligned}
$$

\subsubsection{Inter-axis coefficients}

If the unbiased coefficients, $K_{2}$, are replaced by the consolidated coefficients, $K_{3}$, the relative sensitivities between the three directions, called 'inter-axis coefficients', are obtained:

$$
\begin{aligned}
& \frac{K_{y}}{K_{x}}=K_{3}(y / x)=\left[\left(\frac{K(y / x)}{K(x / y)}\right)^{2} \frac{K(y / z) \cdot K(z / x)}{K(z / y) \cdot K(x / z)}\right]^{1 / 6} \\
& \frac{K_{z}}{K_{x}}=K_{3}(z / x)=\left[\left(\frac{K(z / x)}{K(x / z)}\right)^{2} \frac{K(z / y) \cdot K(y / x)}{K(y / z) \cdot K(x / y)}\right]^{1 / 6} \\
& \frac{K_{z}}{K_{y}}=K_{3}(z / y)=\left[\left(\frac{K(z / y)}{K(y / z)}\right)^{2} \frac{K(z / x) \cdot K(x / y)}{K(x / z) \cdot K(y / x)}\right]^{1 / 6}
\end{aligned}
$$

Equations (13), (14), and (15) are consistent with each other so, for example, Equation (15) can be obtained by dividing Equation (14) by Equation (13).

The ratio in Equation (13) represents sensitivity to lateral vibration relative to sensitivity to fore-and-aft vibration. For example, a ratio of 2.0 would mean that the 
discomfort caused by a fore-and-aft vibration with magnitude $1.0 \mathrm{~ms}^{-2}$ r.m.s. is equivalent to the discomfort caused by a lateral vibration with magnitude $0.5 \mathrm{~ms}^{-2}$ r.m.s. This would mean that in order to compare a $4-\mathrm{Hz}$ fore-and-aft vibration with a $4-\mathrm{Hz}$ lateral vibration, the weighting for lateral vibration should be double the weighting for fore-and-aft vibration at this frequency. Practically, if frequency weightings are used to evaluate vibrations in different directions, the ratio of the 'lateral' weighting to the 'fore-and-aft' weighting at $4 \mathrm{~Hz}$ should be equal to the coefficient $K_{3}(x, y)=K_{\mathrm{y}} / K_{\mathrm{x}}$. Similarly, the ratio of the 'vertical' weighting to the 'foreand-aft' weighting at $4 \mathrm{~Hz}$ should be equal to the coefficient $K_{3}(x, z)=K_{z} / K_{x}$.

\section{Results}

\subsection{Equivalence coefficients}

For each subject, the six equivalence coefficients calculated with Equation (5) are reported in Table 3. The medians and the inter-quartile ranges of these coefficients are shown in Figure 2. For comparison, the inverse of some of the equivalence coefficients are reported. For example, $K(x / y)^{-1}$ and $K(y / x)$ would be equal if there was no order effect. If, for example, subjects tend to underestimate the discomfort caused by the second motion in a pair (i.e., the test motion), the measured value of $K(y / x)$ will be less than its 'true' value. The measured value of $K(x / y)$ will also be less than its true value, so $K(x / y)^{-1}$ will be greater than its true value, which is equal to the true value of $K(y / x)$. As a consequence, $K(x / y)^{-1}$ will be greater than $K(y / x)$. It can be observed that $K(x / y)^{-1}, K(z / y)^{-1}$, and $K(z / x)^{-1}$ are greater than, respectively, $K(y / x)$, $K(y / z)$ and $K(x / z)$. This suggests that overall, subjects tended to underestimate the discomfort of the test motion (i.e. the second motion).

\section{TABLE 3 AND FIGURE 2 AROUND HERE}

\subsection{Inter-axis coefficients}

The inter-axis coefficients calculated from Equations (13), (14), and (15) using the median equivalence coefficients in Table 3 are shown in Table 4. The inter-axis 
coefficients show the consolidated relative sensitivity between directions of $4-\mathrm{Hz}$ vibration and are compared with similar values derived from the standards and experimental studies with seated people.

\section{TABLE 4 AROUND HERE}

The results show that the standing subjects in the present experiment were less sensitive to lateral vibration than to fore-and-aft vibration $\left(K_{y} / K_{x}<1, p=0.005\right.$, Wilcoxon) and more sensitive to vertical vibration than to fore-and-aft or lateral vibration $(p<0.001)$.

\section{Discussion}

\subsection{Inter-axis coefficients}

For the evaluation of vibration with respect to discomfort, International Standard 2631-1 (1997) and British Standard 6841 (1997) advocate the use of frequency weighting $W_{\mathrm{b}}$ for vertical vibration and frequency weighting $W_{\mathrm{d}}$ for horizontal (fore-aft and lateral) vibration. (In ISO 2631-1, $W_{k}$ is recommended for vertical vibration in general, but $W_{b}$ is advocated for specific applications such as railway vibration). The same frequency weightings are recommended for seated and standing people. Multiplying coefficients (equal to 1.0) are used for all three translation axes. Taking account of the frequency weightings and the multiplying factors, the relative sensitivities assumed in the standards at $4 \mathrm{~Hz}$ are:

$$
\begin{gathered}
\frac{K_{y}}{K_{x}}=\frac{W_{\mathrm{d}(4 \mathrm{~Hz})}}{W_{\mathrm{d}(4 \mathrm{~Hz})}}=1.000 \\
\frac{K_{z}}{K_{x}}=\frac{W_{\mathrm{b}(4 \mathrm{~Hz})}}{W_{\mathrm{d}(4 \mathrm{~Hz})}}=\frac{0.889}{0.512}=1.736 \\
\frac{K_{z}}{K_{y}}=\frac{W_{\mathrm{b}(4 \mathrm{~Hz})}}{W_{\mathrm{d}(4 \mathrm{~Hz})}}=\frac{0.889}{0.512}=1.736
\end{gathered}
$$

Equivalent comfort contours for seated people (18 males, 18 females) exposed to fore-and-aft, lateral, and vertical vibration were constructed by Griffin et al. (1982) 
using a common vertical reference. Their subjects sat with no backrest on a flat wooden seat covered with a thin layer of neoprene to increase friction and from the median judgements of discomfort the relative sensitivity to $4-\mathrm{Hz}$ vibration can be derived:

$$
\begin{aligned}
& \frac{K_{y}}{K_{x}}=0.63 \\
& \frac{K_{z}}{K_{x}}=0.80 \\
& \frac{K_{z}}{K_{y}}=1.26
\end{aligned}
$$

The subjective equivalence of lateral and vertical vibration in seated people (15 men and 11 women) was also investigated by Griefahn and Bröde (1997) who compared their findings with the standards. Subjects sat on a slightly contoured wooden seat without a backrest and were exposed to a vertical sinusoidal reference vibration followed by a lateral sinusoidal test vibration. They were asked to adjust the magnitude of the test vibration until it caused "equal sensation as the reference". The adjusted magnitude was compared with that predicted by ISO 2631-1 (1997) from the ratio of frequency weightings (i.e., $W_{\mathrm{k}} / W_{\mathrm{d}}$ ). The adjusted magnitude was, on average, $7 \mathrm{~dB}$ lower than the expected magnitude at $3.15 \mathrm{~Hz}$, and $4 \mathrm{~dB}$ lower at $6.3 \mathrm{~Hz}$. Over all frequencies investigated (from 1.6 to $12.5 \mathrm{~Hz}$ ), the difference was, on average, around $-6 \mathrm{~dB}$, suggesting the standard overestimated the discomfort caused by vertical vibration compared to the discomfort caused by lateral vibration. The results were similar when $W_{\mathrm{b}}$ was used instead of $W_{\mathrm{k}}$. These findings suggest the frequency weighting $W_{\mathrm{d}}$ should be multiplied by a factor of 2.0 to reflect the inter-axis equivalence between vertical and lateral vibration at $3.15 \mathrm{~Hz}$. When combined with the frequency weightings $W_{\mathrm{b}}$ and $W_{\mathrm{d}}$, this would correspond to an inter-axis coefficient $\left(K_{z} / K_{y}\right)$ at $4 \mathrm{~Hz}$ of about 0.9 . The same procedure was used by Griefahn and Bröde (1997) with fore-and-aft vibration and similar results were obtained, with adjusted magnitudes for fore-and-aft vibration about $6 \mathrm{~dB}$ lower than the expected magnitudes. With the method of adjustment, subjects tend to adjust the vibration to a magnitude lower than the true value, especially when judging high magnitudes of vibration. To take this into account, the authors estimated the bias from judgements obtained when the test motion and the reference motion were in the same direction 
(vertical) and assumed the bias would be the same when the test motion and the reference motion were in different directions.

The studies of Griffin et al. (1982) and Griefahn and Bröde (1997) show differences: whereas Griffin et al. (1982) found seated subjects more sensitive to fore-and-aft vibration than lateral vibration $\left(K_{\mathrm{y}} / K_{\mathrm{x}}=1.64\right)$, Griefahn and Bröde found similar sensitivity in the fore-and-aft and lateral directions. The difference might be due to differing transmission of vibration to the body in the two studies associated with differing sitting postures, differences in the vibration at the feet, differences in the postural support from the feet, differences in the contour and friction at the seat surface.

Similar to the seated subjects of Griffin et al. (1982), the standing subjects in the present study were more sensitive to fore-and-aft vibration than to lateral vibration at $4 \mathrm{~Hz}$ : individual values of $K_{\mathrm{y}} / K_{\mathrm{x}}$ were less than 1.0, and the inter-axis equivalence calculated with the median equivalence coefficients was 0.71 . The increased sensitivity to fore-and-aft vibration at this frequency may be due to postural stability being threatened more by fore-and-aft vibration than by lateral vibration (Thuong and Griffin, 2011b).

Standing people exposed to $4-\mathrm{Hz}$ vibration in the present study, were more sensitive to vertical vibration than to lateral vibration, like the seated subjects of Griffin et al. (1982), but unlike the seated subjects of Griefahn and Bröde (1997). For both seated and standing people, the standards provide $K_{z} / K_{y}$ values greater than 1.0 at $4 \mathrm{~Hz}$, suggesting seated and standing people are more sensitive to vertical vibration than to lateral vibration at this frequency. This is consistent with the results of Griffin et al. (1982) and the present results, although the standards may underestimate sensitivity to vertical vibration in standing people.

It seems reasonable to expect that the direction of $4-\mathrm{Hz}$ vibration will have different effects on standing and seated people. Although the standards suggest similar magnitudes of fore-and-aft and lateral vibration will cause similar discomfort, the results show that standing people are more sensitive to $4-\mathrm{Hz}$ fore-and-aft vibration than to $4-\mathrm{Hz}$ lateral vibration. Similarly, relative to the discomfort caused by horizontal vibration, vertical vibration at $4 \mathrm{~Hz}$ causes more discomfort in standing people than in seated people. 


\subsection{Weightings for multi-axis vibration}

Frequency weightings for standing people exposed to fore-and-aft, lateral, and vertical vibration have been determined previously (Thuong and Griffin, 2011b). The present results can be used to adjust those weightings to show the relative discomfort caused by vibration at different frequencies and in different axes. The frequency weightings reported by Thuong and Griffin (2011b) were adjusted so that the ratios of the weightings at $4 \mathrm{~Hz}$ correspond to the inter-axis coefficients determined in the present study (Table 4). The three frequency weightings obtained by this method for fore-and-aft, lateral, and vertical vibration are shown in Figure 2. The three weightings were multiplied by an identical constant so that the weighting for vertical vibration matched the weighting $W_{\mathrm{b}}$ over the range 2 to $16 \mathrm{~Hz}$ (i.e. the absolute difference was minimised over this range). The relevant weightings advocated in the standards (i.e. $W_{\mathrm{b}}$ and $W_{\mathrm{d}}$ ) are shown for comparison. The weightings for horizontal vibration determined from the experimental studies might be approximated by a line of constant velocity at frequencies less than about $3 \mathrm{~Hz}$, and a line of constant acceleration at higher frequencies, as shown in Figure 2. For convenience, the frequency weightings are tabulated in Table 5.

\section{FIGURE 2 AND TABLE 5 AROUND HERE}

The experimental findings suggest that relative sensitivity to vibration in the three directions differs for standing and seated people. The frequency weightings recommended in current standards for standing people, which are identical to those for seated people and were greatly influenced by the responses of seated people, appear inappropriate, and could be improved.

\subsection{Other factors influencing the inter-axis equivalence of vibration}

\subsubsection{Vibration magnitude}

The coefficients indicating the equivalence between the different directions of vibration were obtained for specific vibration magnitudes. If the rate of growth of sensation, $n$, in Steven's power law (Equation 1) differs between directions, the relative sensitivity between directions will vary with the magnitude of excitation.

The rates of growth of sensation, $n$, were obtained for each subject and each pair of directions. For each direction of the test vibration, the rate of growth was obtained with two reference directions. For none of the test directions did the rate of growth 
depend on the reference direction ( $p>0.1$, Wilcoxon). The average of the two values obtained from the two reference directions was therefore retained. The rates of growth are presented in Table 6 with the median value.

\section{TABLE 6 AROUND HERE}

The exponent, $n$, at $4 \mathrm{~Hz}$ did not depend on the direction of the test vibration $(p>0.17$, Friedman). So the experimental data suggest that over the conditions studied here the relative sensitivity to $4-\mathrm{Hz}$ vibration between directions does not vary significantly with the magnitude of the vibration.

With different frequency weightings for each axis of vibration, the relative sensitivity to vibration in each axis varies with the frequency of vibration. The rate of growth of vibration discomfort depends on the frequency of vibration (Thuong and Griffin, $2011 b$ ). Consequently, although relative sensitivity to $4-\mathrm{Hz}$ vibration does not appear to depend on vibration magnitude, relative sensitivity to some other frequencies of vibration will depend on the magnitude of vibration as well as the frequency of vibration.

The relative sensitivity to vibration in each axis may vary with the duration of vibration, although there are no known studies. If the rate of growth of discomfort depends on the duration of vibration, the relative sensitivity to vibration with durations other than 6 seconds may depend on both the magnitude of vibration and the duration of vibration.

\subsubsection{Postural support}

Passengers in transport rarely stand without using any support. More often, they use a support such as a vertical bar, a back support, or a shoulder support. The effects of such supports on the discomfort of standing people exposed to $4-\mathrm{Hz}$ sinusoidal horizontal vibration, as reported by Thuong and Griffin (2011a), were combined with the present results to investigate their influence on inter-axis coefficients. The median values reported in Table 7 suggest that standing people resting their shoulder against a vibrating wall will be more sensitive to lateral vibration than to fore-and-aft vibration, whereas people leaning with their back against a vibrating wall, or holding a vertical bar, will be more sensitive to fore-and-aft vibration than to lateral vibration.

\section{TABLE 7 AROUND HERE}

\subsubsection{Posture and shoes}


The present and previous findings were obtained with subjects standing with their knees locked (Thuong and Griffin, 2011a, 2011b). Bending the knees increases the transmission of vertical vibration to the head around $3 \mathrm{~Hz}$, probably due to a body resonance, but reduces the transmission of vertical vibration between 5 and $20 \mathrm{~Hz}$ : floor-to-head transmissibility is reduced by more than $10 \%$ when the knees are 'unlocked' and by more than 50\% when the knees are bent (Paddan and Griffin, 1993). Bending of the knees may not affect sensitivity to horizontal vibration to a similar extent, suggesting the relative sensitivity to vibration in the three axes of vibration will depend on whether the knees are 'locked', 'unlocked', or bent. It seems likely that vertical vibration at frequencies greater than about $5 \mathrm{~Hz}$ will cause less discomfort when the knees are bent.

Shoes do not change the transmission of vibration to the body over the range of frequencies studied here (Morioka and Griffin, 2010), but shoes may affect postural stability. Shoes that widen the contact area with the floor may increase stability and reduce discomfort whereas the wearing of high-heel shoes may decrease stability and increase the discomfort caused by low frequency horizontal vibration. Frequency weightings derived from the results obtained here without shoes may therefore not be applicable to all types of footwear.

\section{Conclusions}

The effect of the direction of vibration on the discomfort of standing people exposed to $4-\mathrm{Hz}$ vibration differs from that assumed in current standards and differs from that for seated people. The difference can be explained by the standards being based on studies of the discomfort of seated people. Unlike the guidance in current standards, with vibration stimuli of 6 -s duration, standing people are more sensitive to $4-\mathrm{Hz}$ foreand-aft vibration than to $4-\mathrm{Hz}$ lateral vibration, possibly due to greater postural instability during fore-and-aft vibration. The standards also underestimate the relative importance of vertical vibration to the discomfort of standing people.

Using the frequency-dependence of discomfort determined in a previous study, weightings have been evolved for each of the three directions of translational vibration so as to define a method of predicting the discomfort caused to standing people by vibration in any direction (fore-and-aft, lateral, or vertical) at frequencies in the range 0.5 to $16 \mathrm{~Hz}$. 


\section{Acknowledgements}

This study was conducted with the support of Société Nationale des Chemins de fer Français (SNCF), Paris, France. The assistance of Cedric Gallais is gratefully acknowledged.

\section{References}

British Standards Institution, 1987. Guide to Measurement and evaluation of human exposure to whole-body mechanical vibration and repeated shock. BS 6841:1987.

Fox, J., 2002. Robust regression, in: $A n R$ and S-Plus companion to applied regression, Thousand Oaks, CA.

Griefahn, B., Bröde, P., 1997. Comfort contours: Inter-axis equivalence. J. Sound Vibrat. 204(1), 85-97.

Griffin, M., Whitham, E., Parsons, K., 1982. Vibration and comfort I. Translational seat vibration. Ergonomics 25(7), 603-630.

International Organization for Standardization, 1997. Mechanical vibration and shock - Evaluation of human exposure to whole-body vibration. Part 1: General requirements. ISO 2631-1:1997.

Mistrot, P., Donati, P., Galmiche, J.P., Florentin, D., 1990. Assessing the discomfort of the whole-body multi-axis vibration: laboratory and field experiments. Ergonomics, 33, (12), 1523-1536.

Morioka, M., Griffin, M.J., 2010. Magnitude-dependence of equivalent comfort contours for fore-and-aft, lateral, and vertical vibration at the foot for seated persons. Journal of Sound and Vibration 329, 2939-2952.

Oborne, D.J., Boarer, P.A., 1982. Subjective response to whole-body vibration. The effects of posture. Ergonomics, 25(7), 673-681.

Paddan, G.S., Griffin, M.J., 1993. The transmission of translational floor vibration to the heads of standing subjects. Journal of Sound and Vibration 160(3), 503-521.

Pheasant, S., 1988. Bodyspace: anthropometry, ergonomics and design. Taylor \& Francis, London. 
Stevens, S.S., 1975. Psychophysics: introduction to its perceptual, neural, and social prospects, Transaction Publishers, Oxford.

Thuong, O., Griffin, M.J., 2011a. The vibration discomfort of standing persons: the effect of body supports. P I MECH ENG F-J RAI, 225(2), 228-235.

Thuong, O., Griffin, M.J., 2011b. The vibration discomfort of standing persons: 0.5$16-\mathrm{Hz}$ fore-and-aft, lateral, and vertical vibration. Journal of Sound and Vibration 330(4), 816-826. 
Table 1 The six groups of stimuli pairs

\begin{tabular}{ccc} 
Group & $\begin{array}{c}\text { Direction of } \\
\text { reference motion }\end{array}$ & $\begin{array}{c}\text { Direction of } \\
\text { test motions }\end{array}$ \\
\hline 1 & Fore-and-aft & Lateral \\
\hline 2 & Fore-and-aft & Vertical \\
\hline 3 & Lateral & Fore-and-aft \\
\hline 4 & Lateral & Vertical \\
\hline 5 & Vertical & Fore-and-aft \\
\hline 6 & Vertical & Lateral \\
\hline
\end{tabular}


Table 2 Magnitudes of $4-\mathrm{Hz}$ sinusoidal vibration (m.s $\mathrm{s}^{-2}$ r.m.s.); the magnitudes of the test stimuli increase in steps of $1.5 \mathrm{~dB}$.

\begin{tabular}{lccc} 
& Fore-and-aft & Lateral & Vertical \\
\hline Reference & 0.50 & 0.63 & 0.32 \\
\hline Test magnitude 1 & 0.23 & 0.29 & 0.15 \\
\hline Test magnitude 2 & 0.27 & 0.34 & 0.17 \\
\hline Test magnitude 3 & 0.32 & 0.41 & 0.20 \\
\hline Test magnitude 4 & 0.39 & 0.49 & 0.24 \\
\hline Test magnitude 5 & 0.46 & 0.58 & 0.29 \\
\hline Test magnitude 6 & 0.55 & 0.69 & 0.34 \\
\hline Test magnitude 7 & 0.65 & 0.82 & 0.41 \\
\hline Test magnitude 8 & 0.77 & 0.97 & 0.49 \\
\hline Test magnitude 9 & 0.92 & 1.15 & 0.58 \\
\hline Test magnitude 10 & 1.09 & 1.37 & 0.69 \\
\hline
\end{tabular}


Table 3 Equivalence coefficients calculated with Equation (4)

\begin{tabular}{lrrrrrr} 
& $K(y / x)$ & $K(x / y)$ & $K(z / y)$ & $K(y / z)$ & $K(x / z)$ & $K(z / x)$ \\
\hline Subject 1 & 0.76 & 1.72 & 3.65 & 0.35 & 0.64 & 2.52 \\
\hline Subject 2 & 0.52 & 1.54 & 3.47 & 0.27 & 0.48 & 1.78 \\
\hline Subject 3 & 0.46 & 1.02 & 3.54 & 0.28 & 0.32 & 1.62 \\
\hline Subject 4 & 0.68 & 1.23 & 1.90 & 0.50 & 0.64 & 1.60 \\
\hline Subject 5 & 0.54 & 1.34 & 2.06 & 0.36 & 0.53 & 1.41 \\
\hline Subject 6 & 0.73 & 1.45 & 2.40 & 0.33 & 0.55 & 1.74 \\
\hline Subject 7 & 0.74 & 1.16 & 2.20 & 0.41 & 0.45 & 1.92 \\
\hline Subject 8 & 0.54 & 1.01 & 2.11 & 0.28 & 0.40 & 1.50 \\
\hline Subject 9 & 1.03 & 1.73 & 3.43 & 0.51 & 0.61 & 3.52 \\
\hline Subject 10 & 0.91 & 0.94 & 2.05 & 0.65 & 0.55 & 1.48 \\
\hline Subject 11 & 0.57 & 1.57 & 4.17 & 0.27 & 0.49 & 2.56 \\
\hline Subject 12 & 0.80 & 1.11 & 4.26 & 0.20 & 0.27 & 3.28 \\
\hline $\mathbf{2 5}^{\text {th }}$ percentile & 0.54 & 1.09 & 2.10 & 0.28 & 0.44 & 1.58 \\
\hline Median & 0.71 & 1.29 & 2.92 & 0.34 & 0.51 & 1.76 \\
\hline $\mathbf{7 5}^{\text {th }}$ percentile & 0.77 & 1.55 & 3.57 & 0.43 & 0.57 & 2.53 \\
\hline
\end{tabular}


Table 4 Inter-axis coefficients for 4-Hz vibration calculated with Equations (13), (14) and (15)

\begin{tabular}{llccc} 
& Posture & $K_{\mathbf{y}} / K_{\mathbf{x}}$ & $K_{\mathbf{z}} / K_{\mathbf{x}}$ & $K_{\mathbf{z}} / K_{\mathbf{y}}$ \\
\hline $\begin{array}{l}\text { "Average" (from median } \\
\text { equivalence coefficients) }\end{array}$ & standing & $\mathbf{0 . 7 1}$ & $\mathbf{1 . 9 5}$ & $\mathbf{2 . 7 7}$ \\
\hline \hline Standard recommendation & $\begin{array}{c}\text { seated + } \\
\text { standing }\end{array}$ & 1.00 & 1.74 & 1.74 \\
\hline Griefahn and Bröde (1997) & seated & - & 0.9 & 0.9 \\
\hline Griffin et al. (1982) & seated & 0.63 & 0.80 & 1.26 \\
\hline
\end{tabular}


Table 5 Frequency weightings for standing people obtained by adjusting the results of Thuong and Griffin (2011) using the present data.

\begin{tabular}{cccc}
\hline \multirow{2}{*}{$\begin{array}{c}\text { Frequency } \\
(\mathbf{H z})\end{array}$} & \multicolumn{3}{c}{ Acceleration weighting } \\
\cline { 2 - 4 } & Fore-and-aft & Lateral & Vertical \\
\hline 0.50 & 2.079 & 1.617 & 0.861 \\
\hline 0.63 & 1.491 & 1.155 & 0.777 \\
\hline 0.80 & 1.134 & 0.987 & 0.609 \\
\hline 1.00 & 0.966 & 0.798 & 0.588 \\
\hline 1.25 & 0.777 & 0.609 & 0.525 \\
\hline 1.60 & 0.630 & 0.546 & 0.441 \\
\hline 2.00 & 0.525 & 0.441 & 0.504 \\
\hline 2.50 & 0.462 & 0.357 & 0.483 \\
\hline 3.15 & 0.420 & 0.294 & 0.567 \\
\hline 4.00 & 0.378 & 0.273 & 0.756 \\
\hline 5.00 & 0.399 & 0.231 & 0.882 \\
\hline 6.30 & 0.294 & 0.294 & 1.155 \\
\hline 8.00 & 0.252 & 0.315 & 1.071 \\
\hline 10.00 & 0.252 & 0.315 & 0.924 \\
\hline 12.50 & 0.231 & 0.252 & 0.966 \\
\hline 16.00 & 0.252 & 0.252 & 1.281 \\
\hline
\end{tabular}


Table 6 Rate of growth, $n$, in Stevens' power law for standing subjects exposed to 4$\mathrm{Hz}$ vibration in the fore-and-aft, lateral, and vertical directions.

\begin{tabular}{cccc}
\hline & $\boldsymbol{n}_{\boldsymbol{x}}$ & $\boldsymbol{n}_{\boldsymbol{y}}$ & $\boldsymbol{n}_{\boldsymbol{z}}$ \\
\hline Subject 1 & 1.14 & 0.89 & 1.02 \\
\hline Subject 2 & 2.30 & 2.76 & 1.90 \\
\hline Subject 3 & 2.06 & 1.53 & 1.46 \\
\hline Subject 4 & 0.92 & 0.70 & 1.00 \\
\hline Subject 5 & 1.94 & 2.02 & 1.76 \\
\hline Subject 6 & 1.45 & 1.15 & 1.54 \\
\hline Subject 7 & 1.31 & 0.74 & 1.02 \\
\hline Subject 8 & 2.18 & 2.13 & 2.63 \\
\hline Subject 9 & 1.60 & 1.84 & 1.36 \\
\hline Subject 10 & 2.08 & 0.95 & 1.64 \\
\hline Subject 11 & 0.93 & 0.70 & 0.95 \\
\hline Subject 12 & 1.94 & 1.68 & 1.33 \\
\hline Median & 1.77 & 1.34 & 1.41 \\
\hline
\end{tabular}


Table 7 Inter-axis coefficients for $4-\mathrm{Hz}$ vibration when standing with postural support.

\begin{tabular}{|l|c|}
\hline & $\mathrm{K}_{\mathrm{y}} / \mathrm{K}_{\mathrm{x}}$ \\
\hline Back support & 0.58 \\
\hline Shoulder support & 1.24 \\
\hline Vertical bar & 0.38 \\
\hline
\end{tabular}




\section{Figure captions}

Figure 1 Photograph and model of the experimental setup: subject standing within the safety frame mounted on the 6-degree-of-freedom motion simulator.

Figure 2 Median values and inter-quartile ranges of equivalence coefficients, $K$, for the six pairs of directions.

Figure 3 Frequency weightings obtained by Thuong and Griffin (2011) adjusted by the present results and compared with weightings in standards. 


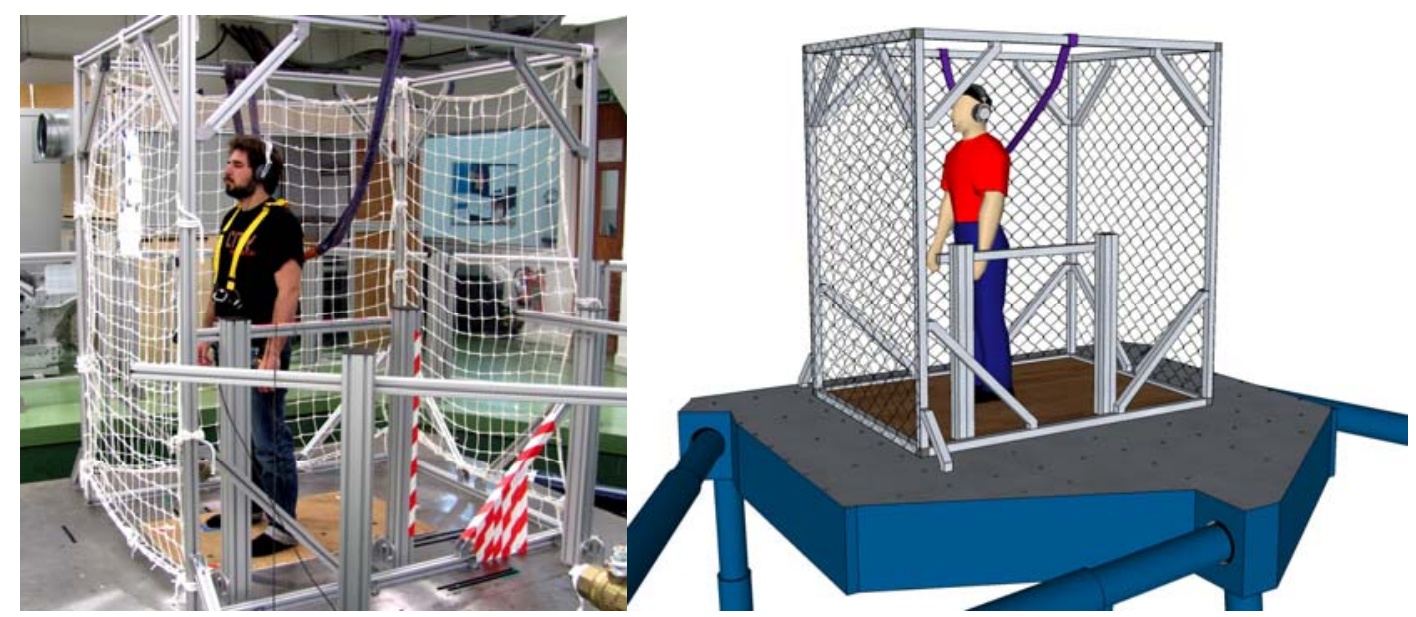

Figure 1 


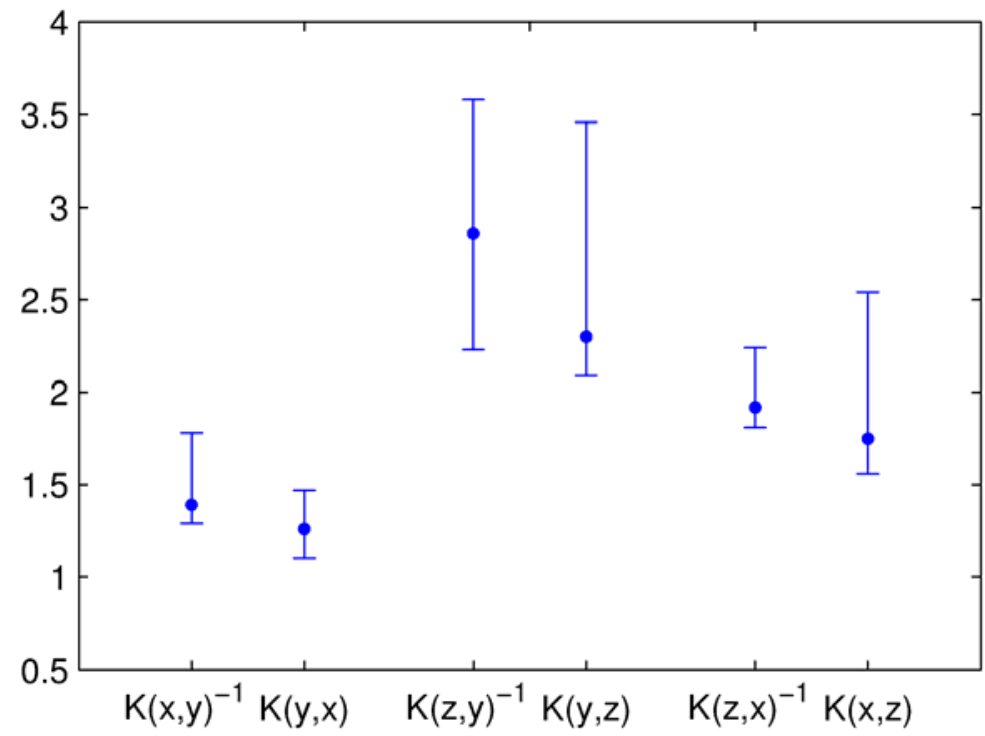

Figure 2 


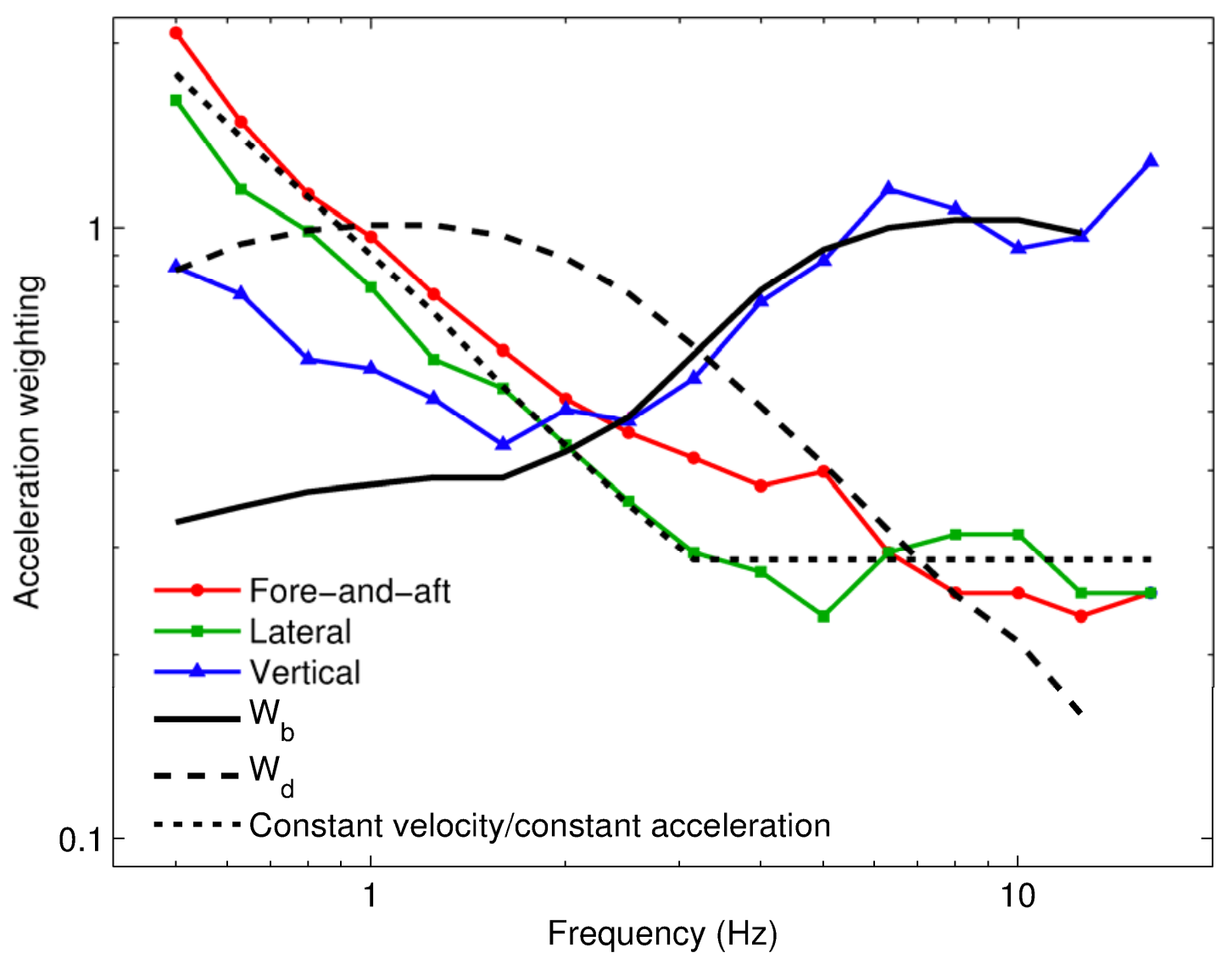

Figure 3 